\title{
Laparoscopic Sleeve Gastrectomy in Patients with Situs Inversus
}

\author{
Dvir Froylich $^{1}$ (D) $\cdot$ Tamar Segal-Abramovich $^{1} \cdot$ Guy Pascal $^{1} \cdot$ David Hazzan $^{1}$
}

Published online: 9 July 2018

(C) Springer Science+Business Media, LLC, part of Springer Nature 2018

\begin{abstract}
Background Situs inversus is a congenital condition in which the major visceral organs are reversed or mirrored from their normal positions. Situs inversus is found in about $0.01 \%$ of the population. In the most common situation, situs inversus totalis involves complete transposition (right to left reversal) of all of the abdominal organs. Several successful and safe laparoscopic weight loss surgeries were previously reported in morbidly obese patients with situs inversus (Aziret et al. Obes Res Clin Pract. 32;11(5S1):144-51, 2017; Catheline et al. Obes Surg.;16(8):1092-5, 2006).

Methods We present a case of a 47 -year-old female patient with a BMI of $51 \mathrm{~kg} / \mathrm{m}^{2}$, who was referred to our clinic for the treatment of morbid obesity. Her past medical history included hypertension, type II diabetes mellitus, asthma, and situs inversus. During the preoperative evaluation, the chest $\mathrm{x}$-ray showed dextrocardia and upper GI series showed the stomach and duodenum in a mirror position.

Results The operative time was $62 \mathrm{~min}$, oral intake started on postoperative day 1, and the patient was discharged on postoperative day 2 in good medical condition.

Conclusions Situs inversus is a rare condition that can be challenging for a laparoscopic surgeon. LSG is feasible and safe for morbidly obese patients with this anomaly. Well understanding of the mirrored image anatomy will facilitate the performance of the procedure without special difficulties by an experienced surgeon.
\end{abstract}

Keywords Bariatric surgery $\cdot$ Sleeve gastrectomy, situs inversus $\cdot$ Morbid obesity $\cdot$ Laparoscopy

\section{Compliance with Ethical Standards}

Conflict of Interest The authors declare that they have no conflict of interest.

Electronic supplementary material The online version of this article (https://doi.org/10.1007/s11695-018-3383-9) contains supplementary material, which is available to authorized users.

Dvir Froylich

dvirfr7@gmail.com

Tamar Segal-Abramovich

T_abramovich@hotmail.com

Guy Pascal

pascalhuy2010@gmail.com

David Hazzan

hazzan2david@yahoo.com

1 Surgery B Department, Carmel Medical Center, 7 Michal Street 3436212, Haifa, Israel

\section{References}

1. Aziret M, Karaman K, Ercan M, et al. Laparoscopic sleeve gastrectomy on a morbidly obese patient with situs inversus totalis: a case study and systematic review of the literature. Obes Res Clin Pract. 2017;11(5S1):144-51.

2. Catheline JM, Rosales C, Cohen R, et al. Laparoscopic sleeve gastrectomy for a super-super-obese patient with situs inversus totalis. Obes Surg. 2006;16(8):1092-5. 